\title{
Evaluation of Self-Care Power in Leprosy Patients
}

\section{Lepra Hastalarında Öz Bakım Gücünün Değerlendirilmesi}

\author{
Hülya Nazik1 ${ }^{1}$ Feride Çoban Gül², Fatih Cem Gül³, Selçuk Nazik, Ramazan Azim Okay5, Mehmet Kamil Mülayim¹, Perihan \\ Öztürk ${ }^{1}$, Betül Demir ${ }^{6}$ \\ 1Kahramanmaraş Sütçü İmam Üniversitesi Tıp Fakültesi, Dermatoloji AD, Kahramanmaraş, Türkiye \\ 2Elazı̆̆ Eğitim ve Araştırma Hastanesi, Dermatoloji Kliniği, Elazı̆̆, Türkiye \\ 3Elazı̆̆ Eğitim ve Araştırma Hastanesi, Göz Kliniği, Elazı̆̆, Türkiye \\ 4Kahramanmaraş Sütçü İmam Üniversitesi Tıp Fakültesi, Enfeksiyon Hastalıkları ve Klinik Mikrobiyoloji AD, Kahramanmaraş, Türkiye \\ 5Kahramanmaraş Sütçü İmam Üniversitesi Tıp Fakültesi, Halk Sağlığı AD, Kahramanmaraş, Türkiye \\ 6Fırat Üniversitesi Tıp Fakültesi, Dermatoloji AD, Elazı̆̆, Türkiye
}

\section{$\ddot{O} Z$}

GİRIŞ ve AMAÇ: Bu çalışmanın amacı cüzzam hastalarında öz bakım gücünün değerlendirilmesi ve öz bakım gücünü etkileyen faktörlerin belirlenmesidir.

YÖNTEM ve GEREÇLER: Çalışma, toplam 26 cüzzam hastasının dahil edildiği tanımlayıcı, kesitsel tipte bir araştırmadır. Hastaların demografik özellikleri ve öz bakım gücü ölçeğine ilişkin verileri karşılıklı görüşme yöntemi ile elde edilmiştir.

BULGULAR: Çalışmaya dahil edilen 27 cüzzam olgusunun \%53,8'inin (n=14) düşük seviyede, $\% 46,2$ 'sinin $(n=12)$ ise orta düzeyde öz bakım gücüne sahip olduğu tespit edildi. Cinsiyet, eğitim durumu, çalışma durumu, ekonomik düzey ve aile yapısı ile öz bakım gücü arasında anlamlı bir ilişki yoktu (sırası ile $p$ değerleri 0,555, 0,636, 0,208, 0,340, 0,951). Öz bakım gücü yaş, hastalık süresi, el-ayak sakatlık evresi ve göz sakatllk evresi ile negatif yönde koreleyken; aile birey sayısıla pozitif yönde koreleydi.

TARTIŞMA ve SONUÇ: Öz bakım gücü, geç tedavi edilmiş ve sekelle sonuçlanmış lepra hastalarında olumsuz etkilenmiştir. Hastaların kendi kendilerine yetebilme gücünün olumsuz etkilendiği sağlık çalışanları tarafindan bilinmeli ve hastaların rehabilitasyonunda göz önünde bulundurulmalıdır.

Anahtar Kelimeler: Cüzzam hastalığl, Lepra sekeli, Öz bakım gücü ölçeğ $i$

\section{ABSTRACT}

INTRODUCTION: Aim of this study is to evaluate selfcare power in leprosy patients and to determine factors that affect self-care power.

METHODS: The study was a descriptive, crosssectional study involving a total of 26 leprosy patients. Data on demographic characteristics and self-care power of the patients were obtained by interview.

RESULTS: It was determined that 53,8\% $(n=14)$ of the 27 leprosy cases included in the study had low self-care power and 46,2\% $(n=12)$ had moderate self-care power. There was no significant relationship between gender, educational status, working status, economic level and family structure and self-care power ( $p$ values 0,555, 0,636, 0,208, 0,340, 0,951, respectively). Selfcare power correlated negatively with age, disease duration, hand-foot disability and eye disability; correlated positively with the number of family members ( $r$ values 0,279, 0,855, 0,619, 0,568, 0,302, respectively).

DISCUSSION AND CONCLUSION: Self-care power was negatively impacted on late-treated and disabled leprosy patients. It should be known by health care providers that self-sufficiency of patients is negatively affected and this should be taken into account in rehabilitation of patients.

Keywords: Leprosy, Leprosy sequelae, Self-care power scale

\section{İletişim / Correspondence:}

Dr. Hülya Nazik

Kahramanmaraş Sütçü Imam Üniversitesi Tip Fakültesi, Dermatoloji AD, Kahramanmaraş, Türkiye

E-mail:dr.hulyagul@hotmail.com

Başvuru Tarihi: 20.10.2017

Kabul Tarihi:23.02.2018 


\section{GIRIŞ}

Cüzzam, Mycobacterium lepra'nın neden olduğu kronik bir enfeksiyon hastalığıdır. Tedavisi mümkün olan bir hastalık olmasına rağmen halen tüm dünyada karşılaşılmaktadır. 2015 yılında dünya genelinde 210758 yeni vaka tespit edildiği bildirilmiştir. Patojen esas olarak deri ve periferik sinir sistemini etkiler. Hastal1k seyri bireysel konak immünitesi ile belirlenir. Erken tedavi ile sekelsiz iyileşme sağlanır. Ancak tanı ve tedavide geç kalındığında ilerleyici fiziksel, psikolojik ve sosyal sakatlıklara yol açabilmektedir (1). Hastalığa bağlı morbiditeler hastanın kendine olan saygisını ve yaşamını olumsuz etkiler (2).

Öz bakım gücü, kişinin hayatını, sağlığını ve mevcut durumunu idame ettirmek için gerekli olan aktiviteleri yapabilme yeteneğidir (3). Lepra hastalarında fiziksel, ruhsal, sosyal ve ekonomik durumun etkilenmesi hayatın devamını sağlamada gerekli ihtiyaçların karşılanmasını olumsuz etkileyebilir. Dolayısıyla öz bakım gücünün azalmasına neden olabilir. Bu çalışmada cüzzam hastalarında hastalığın öz bakım gücüne etkisinin değerlendirilmesi amaçlanmıştır.

\section{GEREÇ VE YÖNTEM}

$\mathrm{Bu}$ çalışma cüzzam hastalarının öz yeterlilik ve öz bakım gücünü tanımlamak için yapılan kesitsel tipte tanımlayıcı bir araştırmadır. Çalışmanın yapılabilmesi için 22/03/2016 tarihli, 06 toplantı sayıl1, 14 karar numaralı yerel etik kurul onay1 alındı. Çalışmaya Temmuz 2016 ile Ocak 2017 tarihleri arasında Elazı̆̆ Eğitim Araştırma Hastanesi Lepra Servisinde lepra tanısı ile tedavi almış ve tedavisi tamamlanan18 yaşından büyük hastalar alındı. Olgular çalışma hakkında bilgilendirildi ve gönüllü olur formu dolduruldu. Hastaların sakatlık düzeyinin belirlenmesi amaciyla, göz ve dermatoloji kliniklerinde muayeneleri yapıldı. Göz muayenesinde öncelikle fasiyal ve oküler deformiteler kaydedildi, ardından Snellen eşeli ile görme keskinliğine bakıldı. Göz kapağının pozisyonu, 1ş1k refleksi, pupil büyüklüğü ve şekli kaydedildi. Daha sonra hastalar yarıklı lamba biyomikroskopu ile muayene edildi. Korneal duyarlılık pamuklu çubuk kullanılarak saptandı. Floresein kullanılarak gözyaşı defekti ve korneal ülser tespit edilmeye çalışıldı. Ön segment bulguları kaydedildi. Göz içi basıncı aplanasyon tonometrisi yardımıyla ölçüldü. \%1'lik tropikamid damlatılarak pupil dilate edildi ve fundus muayenesi yapıldı. Dermatoloji kliniğinde yüzeyel duyu muayeneleri yapıldı. Dokunma duyusu pamuk yardımı ile, ağrı duyusu sivri uçlu bir iğne ile, 1sı duyusu ise ayrı iki şişedeki sıcak su ve soğuk su deriye temas ettirilerek yapıld1. Dokunma duyusu muayene edilirken, öncelikle pamuk vücudun rastgele bir yerine hastanın gözleri açık iken dokundurulup uyarı öğretildi. Sonra hastanın gözleri kapatılıp pamuğu yüz, gövde ve ekstremitelerin tamamında gezdirerek duyu hasarı olan bölgenin sınırları belirlendi. Ağr1 ve 1s1 muayeneleri yapılırken de öncelikle uyarı öğretilip daha sonra duyu kaybının olduğu alanlar tespit edildi. El ve ayak deformitesi açısından inspeksiyon yoluyla değerlendirildi ve fonksiyonel sakatlığa yol açacak tenar, hipotenar atrofi, kemik rezorbsiyonu, derin ülser, otoamputasyon varlığı kaydedildi. Hastalardaki sakatlığın evrelenmesinde Dünya Sağlık Örgütünün cüzzam hastaları için önerdiği yöntem kullanılmıştır (4). Dünya sağlık örgütünün lepra hastaları için önerdiği sakatlık evrelemesi Tablo 1'de verilmiştir.

\begin{tabular}{|c|c|c|}
\hline & El-ayak sakatlığı & Göz sakatlığı \\
\hline Evre 0 & $\begin{array}{l}\text { Duyusal-fonksiyonel } \\
\text { sakatlık yok }\end{array}$ & $\begin{array}{l}\text { Lepraya bağlı göz } \\
\text { problemi yok } \\
\text { Görme kaybı yok }\end{array}$ \\
\hline Evre 1 & $\begin{array}{c}\text { El veya ayakta duyu } \\
\text { kaybı var } \\
\text { Görünür deformite yok }\end{array}$ & $\begin{array}{c}\text { Lepraya bağlı göz } \\
\text { problemi var } \\
\text { Şiddetli görme hasarı } \\
\text { yok }\end{array}$ \\
\hline Evre 2 & $\begin{array}{c}\text { El veya ayakta duyu } \\
\text { kaybı var } \\
\text { Görünür deformite var }\end{array}$ & $\begin{array}{l}\text { Şiddetli görme hasarı } \\
\text { var }\end{array}$ \\
\hline
\end{tabular}

Olguların yaş, cinsiyet, hastalık süresi, eğitim durumu (ilkokul mezunu, ortaokul mezunu ve yüksek okul mezunu olarak üç gruba ayrıldı), çalışma durumu (herhangi bir işte çalışabiliyor veya çalışamıyor olmasına göre iki gruba ayrıldı), ekonomik düzey (düşük, orta, yüksek olarak üç gruba ayrıldı), aile yapısı (çekirdek aile, geniş aile ve parçalanmış aile olmak üzere üç gruba ayrıldı), ailedeki birey sayısı gibi özellikleri sorgulanarak kaydedildi. Öz bakım gücü ölçeği ile ilgili veriler hastaların vizüel problemleri, fiziksel deformiteleri dikkate alınarak karşılıklı görüşme yöntemi ile elde edildi. Hastalardan alkol bağımlılığı olanlar, diyabet 
hastaları, başka bir sebepten nöromüsküler hastalığ 1 olanlar ve zihinsel bozukluğu olanlar çalışmaya dahil edilmedi.

Kearney ve Fleischer tarafindan oluşturulan öz bakım gücü ölçeği, kişilerin kendine bakabilme yetisi ve gücünü tespit etmeyi hedefleyen bir ölçektir. Ölçeğin Türkiye'deki geçerlilik ve güvenirlik çalışması sağlıklı bireylerde 2004 yılında Nahcivan tarafından, kronik hastalıklarda 1997 yılında Pınar tarafından yapıldı. Kişiler 35 maddeyi içeren bu ölçekte, öz bakım faaliyetleri ile meşgul olma durumlarını ifade eden ibareyi tercih eder. Ölçek, değişen yanıt seçeneklerini kullanarak tutum ve davranışları ölçen likert tiptedir. Ölçekteki her ibare sıfırdan dörde kadar puanlanır (beni hiç tanımlamıyor $=0$ puan, beni pek tanımlamıyor $=1$ puan, fikrim yok $=2$ puan, beni biraz tanımlıyor $=3$ puan, beni tam tanımlıyor=4 puan). Ölçeğin puanı 82 den az ise düşük, 82-120 arası ise orta, 120 den büyük ise yüksek öz bakım gücünü ifade eder (5).

Çalışmada elde edilen veriler SPSS v.17.0 paket programı (SPSS Inc, Chicago, Illinois, USA) ile istatistiksel olarak analiz edildi. Sürekli veriler ortalama, standart sapma şeklinde; kategorik veriler ise sayı ve yüzde olarak belirtildi. Gruplar arası karşılaştırmalar için; kategorik iki bağımsız grubun değerlendirilmesinde ki-kare $\left(\chi^{2}\right)$ testi, nonkategorik iki bağımsız grubun değerlendirilmesinde Student-t testi, gruplar arasındaki korelasyonun değerlendirilmesinde Pearson korelasyon analiz testi kullanıldı. İstatistiksel anlamlılık düzeyi olarak $\mathrm{p}<0,05$ değeri alındı.

\section{BULGULAR}

Çalışmaya 18 erkek $(\% 69,2), 8$ kadın $(\% 30,8)$ toplam 26 katılımc1 dahil edildi. Katılımcıların $\% 19,2$ 'sinde ailede hasta dışında lepralı başka bir bireyle yaşama öyküsü varken, \%80,8'inde ailede hasta dışında lepralı başka bir birey yoktu. Katılımcıların ortalama öz bakım gücü toplam skoru $81,31 \pm 15,2 \quad$ (min-max:54-103) idi. Katılımcıların öz bakım gücü değerlendirildiğinde $\% 53,8$ 'inin $(\mathrm{n}=14)$ düşük seviyede olduğu, $\% 46,2$ 'sinin $(n=12)$ ise orta düzeyde olduğu saptanmıştır. Öz bakım gücü yüksek olan olgu yoktu. Katılımcıların yaş ortalamas $10,77 \pm 11,86$ yıl (minimum-maksimum: 40-99 yıl) idi. Yaş ve öz bakım gücü toplam skoru arasındaki ilişki değerlendirildiğinde aralarında negatif yönde korelasyon vard1 $(r=0,279, p=0,168)$. Kat1limcilara ait veriler ile öz bakım gücü arasındaki ilişki durumu Tablo 2'de sunulmuştur.

\begin{tabular}{|c|c|c|c|c|}
\hline $\begin{array}{c}\text { Katılımcılara } \\
\text { Ait Özellikler } \\
\qquad(n=26)\end{array}$ & $\begin{array}{l}\text { Düşük } \\
(n=14)\end{array}$ & $\begin{array}{c}\text { Orta } \\
(n=12)\end{array}$ & p* & $r^{* *}$ \\
\hline \multicolumn{5}{|l|}{ Yaş } \\
\hline $40-49$ & $0(\% 0)$ & $2(\% 100)$ & \multirow{5}{*}{0,168} & \multirow{5}{*}{0,279} \\
\hline $50-59$ & $2(\% 66,7)$ & $1(\% 33,3)$ & & \\
\hline $60-69$ & $1(\% 100)$ & $0(\% 0)$ & & \\
\hline $70-79$ & $9(\% 50)$ & $9(\% 50)$ & & \\
\hline$>80$ & $2(\% 100)$ & $0(\% 0)$ & & \\
\hline \multicolumn{5}{|l|}{ Cinsiyet } \\
\hline Erkek & $9(\% 50)$ & $9(\% 50)$ & \multirow{2}{*}{0,278} & \\
\hline Kadın & $5(\% 62,5)$ & $3(\% 27,5)$ & & \\
\hline \multicolumn{5}{|l|}{ Eğitim durumu } \\
\hline ilkokul & $12(\% 52,2)$ & $11(\% 47,8)$ & \multirow{2}{*}{0,998} & \\
\hline Ortaokul & $2(\% 66,7)$ & $1(\% 33,3)$ & & \\
\hline \multicolumn{5}{|l|}{$\begin{array}{l}\text { Çalışma } \\
\text { durumu }\end{array}$} \\
\hline Çalışıyor & $1(\% 25,0)$ & $3(\% 75,0)$ & \multirow{2}{*}{0,208} & \\
\hline Çalışmıyor & $13(\% 59,1)$ & $9(\% 40,9)$ & & \\
\hline \multicolumn{5}{|l|}{$\begin{array}{l}\text { Sosyo- } \\
\text { ekomomik } \\
\text { durum }\end{array}$} \\
\hline Düşük & $6(\% 66,7)$ & $3(\% 33,3)$ & \multirow{2}{*}{0,340} & \\
\hline Orta & $8(\% 47,1)$ & $9(\% 52,9)$ & & \\
\hline \multicolumn{5}{|l|}{ Aile yapısı } \\
\hline Çekirdek & $0(\% 0)$ & $7(\% 26,9)$ & \multirow{3}{*}{0,001} & \\
\hline Geniş & $7(\% 26,9)$ & $5(\% 19,2)$ & & \\
\hline Parçalanmış & $7(\% 26,9)$ & $0(\% 0)$ & & \\
\hline \multicolumn{5}{|l|}{ Aile birey sayısı } \\
\hline $1-5$ & $8(\% 30,8)$ & $5(\% 19,2)$ & \multirow{3}{*}{0,134} & \multirow{3}{*}{0,302} \\
\hline $6-10$ & $4(\% 15,4)$ & $3(\% 11,5)$ & & \\
\hline 11 ve üstü & $2(\% 7,7)$ & $4(\% 15,4)$ & & \\
\hline \multicolumn{5}{|l|}{ Hastalık süresi } \\
\hline $9-14$ & $0(\% 0)$ & $5(\% 19,2)$ & \multirow{3}{*}{0,000} & \multirow{3}{*}{0,855} \\
\hline $15-21$ & $7(\% 26,9)$ & $7(\% 26,9)$ & & \\
\hline $22-28$ & $7(\% 26,9)$ & $0(\% 0)$ & & \\
\hline \multicolumn{5}{|l|}{$\begin{array}{c}\text { El-ayak sakatlık } \\
\text { evresi }\end{array}$} \\
\hline Evre1 & $0(\% 0)$ & $5(\% 19,2)$ & \multirow{2}{*}{0,001} & \multirow{2}{*}{0,619} \\
\hline Evre 2 & $14(\% 53,8)$ & $7(\% 26,9)$ & & \\
\hline \multicolumn{5}{|l|}{$\begin{array}{c}\text { Göz sakatlık } \\
\text { evresi }\end{array}$} \\
\hline Evre 0 & $2(\% 7,7)$ & $2(\% 7,7)$ & \multirow{3}{*}{0,000} & \multirow{3}{*}{0,568} \\
\hline Evre 1 & $3(\% 11,5)$ & $6(23,1)$ & & \\
\hline Evre 2 & $6(23,1)$ & $7(26,9)$ & & \\
\hline
\end{tabular}

Cinsiyet ve özbakım gücü toplam skoru arasındaki ilişki değerlendirildiğinde; erkeklerde ortalama skor $83,5 \pm 14,0$, kadınlarda ortalama skor $76,4 \pm 17,7$ idi. Öz bakım gücü toplam skoru ile cinsiyet arasında istatistiksel olarak anlamlı bir fark yoktu $(p=0,278)$. Olguların hastalık süresi 
değerlendirildiğinde ortalama hastalık süresinin 18,46 $\pm 5,32$ y1l (min-max:9-28 y1l) olduğu tespit edildi. Hastalık süresi, öz bakım gücü ile negatif yönde korele idi $(r=-0,855, \mathrm{p}=0,000)$.

Tamamı kırsal bölgede yaşayan katılımcıların eğitim durumları değerlendirildiğinde $\% 88,5$ 'inin $(n=23)$ ilkokul mezunu olduğu, \%11,5'inin $(n=3)$ ise ortaokul mezunu olduğu buna karşın lise ve yüksekokul mezununun olmadığı tespit edildi. Eğitim durumu ile öz bakım gücü toplam skoru arasında istatistiksel olarak anlamlı bir fark yoktu $(\mathrm{p}=0,998)$.

Katılımcıların çalışma durumları incelendiğinde \%15,4'ünün ( $\mathrm{n}=4)$ çalışabildiği, \%84,6'sının ( $\mathrm{n}=22)$

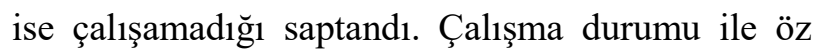
bakım gücü toplam skoru kıyaslandığında iki grup arasında istatistiksel olarak anlamlı fark olmadığ tespit edildi ( $p=0,208)$. Çalışmayan 22 olgu sakatlık durumuna göre değerlendirildi. El-ayak sakatlık evresine göre 1 olgu $(\% 3,8)$ evre 1,21 olgu $(\% 80,8)$ ise evre 2 idi. Göz sakatlık evresine göre 9 olgu $(\% 34,6)$ evre1, 13 olgu (\%50) ise evre 2 idi. Elayak sakatlık evresi ve göz sakatlık evresi daha ileri olanların istatistiksel olarak anlamlı derecede daha yüksek oranda çalışmadığı tespit edildi (sırasıyla $\mathrm{p}=0,000, \mathrm{p}=0,000$ ). Çalışabilen 4 olgunun sakatlık durumuna bakıldığında olguların tamamının el ayak sakatlık evresi evre 1, göz sakatlık evresi ise evre 0 idi. El-ayak ve göz sakatlık evresi ile öz bakım gücü arasında negatif yönde korelasyon vard1 (surasiyla $\mathrm{r}=-0,619, \mathrm{p}=0,001 ; \mathrm{r}=-0,568, \mathrm{p}=0,000$ ).

Hastalar ekonomik düzey açısından değerlendirildiğinde \%34,6's1 (n=9) orta düzeyde, \%65,4'ü $(n=17)$ ise düşük düzeyde idi. Öz bakım gücü ile ekonomik düzey arasında istatistiksel olarak anlamlı fark yoktu $(\mathrm{p}=0,340)$.

Katılımcıların \%26,9'u (n=7) çekirdek aile yapısında, \%46,2 'si $(\mathrm{n}=12)$ ise geniş aile yapısında, $\% 26,9$ 'u $(n=7)$ ise parçalanmış aile yapısında idi. Aile yapısı ile öz bakım gücü arasında istatistiksel olarak anlamlı bir ilişki vardı $(p=0,001)$. Ailedeki birey sayısı ile öz bakım gücü ile pozitif yönde korele idi $(r=0,302, p=0,134)$.

\section{TARTIŞMA}

Lepra hala ihmal edilen önemli bir halk sağlığ problemidir. Erken tedavi edilmezse, özürlülüğe ve fonksiyonel kısitlamaya neden olur. Dünyada tahmini olarak üç milyon kişide, cüzzama bağlı gelişen deformite mevcuttur. Dolayısı ile cüzzam önlenebilir sakatllğğn önemli bir nedenidir (6).

Öz bakım gücünün yüksek olması bireylerin kimseye bağımlı olmaksızın kendi ihtiyaçlarını karşılamasını yani kendi kendine yetebilmeyi ifade eder (7). Çalışmaya dahil edilen tüm lepra olgularında, öz bakım gücünün düşük ve orta düzeyde olduğu tespit edildi. Olguların hiçbiri yüksek öz bakım gücüne sahip değildi. Öz bakım gücü ile hastalık süresi, yaş ve sakatlık evresi arasında negatif yönde; ailedeki birey sayısı ile pozitif yönde korelasyon vardı. Buna karşın hastalarda cinsiyet, eğitim durumu, çalışma durumu ve ekonomik düzey araştırıldığında öz bakım gücü ile aralarında anlamlı bir ilişki olmadığı sonucuna varıld.

Cinsiyet ile öz bakım gücü arasındaki ilişkiye bakıldığında literatürde farklı sonuçlar bulunmaktadır. Huzurevinde yaşayan bireylerde öz bakım gücünün araştırıldığ 1 bir çalışmada kadınlarda ve ileri yaşta öz bakım gücü daha az olmasına rağmen istatistiksel olarak anlamlı bir fark oluşturmamıştır (8). Düzöz ve arkadaşları tarafindan Tip 2 diyabetli hastalarda yapılan bir çalışmada öz bakım gücü ile cinsiyet arasında anlamlı bir ilişki bulunmamıştır (9). Karakurt ve arkadaşları tarafından diyabetli hastalarda yapılan başka bir çalışmada ise öz bakım gücü kadınlarda daha yüksek bulunmuştur (10). Bu çalışmada kadın cinsiyette ve ileri yaşta öz bakım gücü anlamlı bir fark olmaksızın daha düşüktü. Altıparmak ve arkadaşları akciğer kanserli hastalarda öz bakım gücünü ve etkileyen faktörleri araştırmışlardır. Çalışmalarında eğitim durumu yüksek olanların öz bakım gücünün daha iyi olduğu sonucuna varmışlardır (11). Bu çalışmada öz bakım gücü düşük olanların eğitim düzeyi daha düşük olmasına rağmen istatistiksel olarak anlamlı fark oluşmadı. Lepranın toplumda nadir görülmesine bağlı olarak çalışma grubundaki hastaların sayısının az olmasının bu durum ile ilişkili olabileceği düşünüldü. Van brakel ve arkadaşları yaptıkları çalışmada tedavisi tamamlanmış lepra hastalarında 
engelliliği ve buna etkisi olacak faktörleri araştırmışlardır. Hastalığın ciddi sosyal damgalama, izolasyon, psikolojik sorunlar ve çalışma yeteneğini azalttığı sonucuna varmışlardır (12). Literatür ile uyumlu olarak bu çalışmada da lepra olgularının \%84,6'sı çalışmamakla birlikte çalışma durumu ile öz bakım gücü arasında anlamlı fark oluşmadı.

Kişinin sosyal ortamında kendisine en yakın bireylerden oluşan aile yapısı, sağlığı koruma ve geliştirme uygulamalarının öğrenildiği ve desteklendiği bir yapıdır. Gebelerde öz bakım gücünün araştırıldığ yapısına sahip olanlarda öz bakım gücünün daha yüksek olduğu tespit edilmiştir (13). Bu çalışmada da literatüre benzer şekilde çekirdek aile yapısına sahip olanlarda öz bakım gücü daha yüksekti.

Çoklu ilaç tedavileri ile cüzzam tedavi edilebilir ve eğer erken teşvik edilirse sakatlığı önleyebilir. Bununla birlikte, cüzzam hala çok geç tanı alan ve tanı konulduğunda zaten kalıcı bozuklukların geliştiği bir hastalıktır (14). Literatüre benzer şekilde bu çalışmadaki olguların tamamında el ve ayakta evre 1 ve evre 2 düzeyinde sakatlık mevcuttu. Yirmi iki olguda ise göz sakatlığ mevcuttu. Cüzzam ile ilişkili fiziksel bozukluk, M. lepra'ya bağlı kronik granülomatözinflamasyondan kaynaklanan sinir hasarına sekonderdir. Bozukluklar, el, ayak ve göz ile ilgili faaliyetlerin k1sitlanması ve sosyal katılımda kisitlamalar gibi engellerin ortaya çıkmasına neden olabilir (15). Bu çalışmada lepralı olguların \%84,6'sında evre 1 ve 2 düzeyinde el-ayak ve göz sakatlı̆̆ 1 tespit edildi. Öz bakım gücü ve çalışan hasta oranının düşük olması hastaların fiziksel yeterliliğini etkileyen el-ayak ve göz sakatlığı ile ilişkilendirildi. Santos ve arkadaşları tarafindan yapılan çalışmada, cüzzam hastalarında aktivite kısıtlılığının taranması ve güvenlik bilinci ölçeği kullanarak yaşam kalitesi ve fonksiyonel aktivite sınırlamaları arasındaki ilişki araştırılmıştır. Çalışmada düşük yaşam kalitesinin özellikle fiziksel ve çevresel alanlarda fonksiyonel aktivite sınırlanması ile ilişkili olduğu sonucuna varılmıştır (16). Borges ve arkadaşları tarafindan yapılan çalışmada cüzzamlı hastalarda yaşam kalitesi, nöropati ve sosyal dışlanma algısı araştırılmıştır. Araştırmanın sonucunda, hem nöropati hem de sosyal dışlanma algısı varlığının yaşam kalitesini önemli ölçüde bozduğu ortaya konulmuştur (17). Bu çalışmada olguların tamamı kırsal bölgede yaşamakta olup çok sayıda insanın birbiriyle daha çok etkileşim halinde olduğu kentsel yaşam tarzını tercih etmemiştir. Lepramatözlepralı hastalarda yaşam kalitesinin değerlendirildiği bir çalışmada, göz sakatlık evresi arttıkça yaşam kalitesinin olumsuz etkilendiği tespit edilmiştir (18). Bu çalışmada yaşam kalitesine benzer şekilde öz bakım gücü ile el-ayak ve göz sakatlık evresi negatif yönde korele idi.

Hemodiyaliz uygulanan hastalarda öz bakım gücünün değerlendirildiği bir çalışmada, hastalık süresi 13 yıldan uzun olan bireylerde öz bakım gücü puanlarının anlamlı derecede düştüğü tespit edilmiştir (7). Tip 1 diyabetesmellituslu bireylerde yapılan bir diğer çalışmada da hastalık süresi uzadıkça öz bakım gücünün azaldığı saptanmıştır. Yazarlara göre bu durum kişinin hastalığın edinildiği ilk zamanlarda gördüğü destek ve iyileşeceğine dair inancının azalması ile ilişkilendirilmiştir (10). $\mathrm{Bu}$ çalışmada lepralı hastalarda öz bakım gücü yaş ve hastalık süresi ile negatif yönde korele idi. Hastalık süresi ve yaş arttıkça öz bakım gücünün azalması, sakatlık evresinin artması ile ilişkilendirildi.

Kronik ve sekellerin eşlik ettiği bir hastalık olan cüzzam hastalığının yönetiminde öz bakım gücü önemli bir yere sahiptir. Cüzzamın tedavisi ve rehabilitasyonunda yer alan tüm sağlık çalışanları hastaların içinde bulunduğu psikolojik ve sosyal durumu göz önünde bulundurarak hastaların öz bakım gücünü yükseltmeye çalışmalıdır.

\section{KAYNAKLAR}

1. Fischer M. Leprosy-an overview of clinical features, diagnosis, andtreatment. J Dtsch Dermatol Ges 2017; 15(8): 801-27.

2. Budel AR, Raymundo AR, Costa CF, et al. Profile of patients affected by Hansen's diseasese en at the Outpatient Clinic of Dermatology at Hospital Evangelico de Curtiba. An Bras Dermatol 2011; 86: 942-46.

3. Kaya H. Öz bakım değerlendirme ölçeğinin (ÖBDÖ) dil eşdeğerliği ve güvenirliği. Hemşirelik Bülteni 2005; 13: 139- 48. 
4. Brandsma JW, Van Brakel WH. WHO disability grading: operational definitions. Lepr Rev 2003;74:366-73.

5. Y1lmaz SD, Beji NK. Gebelikte öz bakım gücünün değerlendirilmesi. Genel Tıp Derg 2010;20(4): 137-42.

6. Britton WJ, Lockwood DN. Leprosy. Lancet 2004; 363: 1209-19.

7. Mohammadpour A, RahmatiSharghi N, Khosravan S, et al. Theeffect of a supportive educational intervention developed based on the Orem's self-care theory on the self-care ability of patients with myocardial infarction: a randomised controlled trial. J Clin Nurs. 2015;24(11-12):168692.

8. Altay B, Avc1 IA. The relation between the self care strength and life satisfaction of the elderly living in nursing home. Dicle Med J 2009; 36 (4): 275-82.

9. Düzöz GT, Çatalkaya D, Uysal DD. Tip 2 Diabetes Mellituslu hastaların öz-bakım gücünün değerlendirilmesi. Yeni Tip Dergisi 2009;26:210-3. 6.

10. Karakurt P, Aşılar RH, Yıldırım A. Diyabetli hastaların öz bakım gücü ve algıladıkları sosyal desteğin değerlendirilmesi. ADÜ Tıp Fakültesi Dergisi 2013; 14(1) : 1 - 9 .

11. Altıparmak S, Fadıloğlu Ç, Gürsoy ŞT, et al. Kemoterapi tedavisi alan akciğer kanserli hastalarda öz bakım gücü ve yaşam kalitesi ilişkisi. Ege Journal of Medicine 2011; 50 (2): 95-102.

12. Van Brakel WH, Sihombing B, Djarir $H$, et al. Disability in people affected by leprosy: the role of impairment, activity, social participation, stigma and discrimination. GlobHealth Action 2012; 5: 111.

13. Altıparmak S. Gebelerde sosyo-demografik özellikler, öz bakım gücü ve yaşam kalitesi ilişkisi. TAF Preventive Medicine Bullet in 2006; 5 (6):416-23.

14. World HealthOrganisation. Global Strategy for Further Reducing the Leprosy Burden and Sustaining Leprosy Control Activities. Operational Guidelines.2006.http://www.who.int/lep/resources/ SEAGLP20062.pdf Son ulaşım tarihi 20.10.2017.
15. Wilder Smith EP, Van Brakel WH. Nervedamage in leprosy and its management. Nat Clin Pract Neurol 2008; 4: 656-63.

16. Santos VS, Oliveira LS, Castro FD, et al. Functional Activity Limitation and Quality of Life of Leprosy Cases in an EndemicArea in North easternBrazil. PLoSNegl Trop Dis 2015; 9(7): e0003900.

17. Borges de Oliveira R, RochaLeite CI, Araujo de Freitas L, et al. Perception of socialexclusion, neuropathy, andquality of life among Hansen's disease patients. Int J Psychiatry Med 2015;49(3):176-86.

18. Betül Demir, Haydar Uçak, Selma Bakar Dertlioğlu, et al. Lepromatöz lepralı hastaların yaşam kalitesi. Türkderm 2014; 48: 146-51. 